\title{
BMJ Global Health Primary healthcare in the time of COVID-19: breaking the silos of healthcare provision
}

\author{
Susan B Rifkin (D) ,' Meredith Fort, ${ }^{2}$ Walaiporn Patcharanarumol, ${ }^{3}$ \\ Viroj Tangcharoensathien ${ }^{3}$
}

To cite: Rifkin SB, Fort M, Patcharanarumol W, et al. Primary healthcare in the time of COVID-19: breaking the silos of healthcare provision. BMJ Global Health 2021;6:e007721. doi:10.1136/ bmjgh-2021-007721

Received 15 October 2021 Accepted 19 0ctober 2021

A) Check for updates

(c) Author(s) (or their employer(s)) 2021. Re-use permitted under CC BY-NC. No commercial re-use. See rights and permissions. Published by BMJ.

${ }^{1}$ Distance Learning, London School of Hygiene and Tropical Medicine, London, UK ${ }^{2}$ Colorado School of Public Health, Aurora, Colorado, USA ${ }^{3}$ International Health Policy Program, Ministry of Public Health, Nonthaburi, Thailand

Correspondence to Dr Susan B Rifkin; sbrifkin@gmail.com

\section{INTRODUCTION}

In 1948, the WHO was created under the aegis of the United Nations (UN) as the agency to address global health concerns. Health was defined as a 'state of complete physical, mental and social well-being and not merely the absence of disease or infirmity'. ${ }^{1}$ In 1978 with the Alma Ata Declaration, the member states of the UN began a process to translate this definition into reality by mandating primary healthcare (PHC) as the health policy for the organisation. PHC highlighted the principles of equity, community participation, and included multisectoral approaches. ${ }^{2}$

Over the first 40 plus years, PHC had various iterations but in most settings focused on primary care health services at the local level now linked to universal health coverage (UHC). This linear and siloed focus misses the original intent of the Alma Ata Declaration. With the COVID-19 pandemic, the focus has proved inadequate. Health services have not prevented the loss of 4 million lives ${ }^{3}$ and the loss of livelihoods of million more people. ${ }^{45}$ This situation also highlights the necessity of addressing health improvements in the context of the social determinants of health and governance. ${ }^{6}$

On the 40th anniversary of the Alma Ata Declaration in 2018, member countries of WHO signed the Astana Declaration. ${ }^{8}$ The declaration focuses on promoting PHC through (a) providing primary care services throughout the life course, (b) ensuring equity for healthcare, (c) addressing the social determinants of health, and (d) empowering citizens and communities. ${ }^{9}$ To pursue these objectives in the post-COVID-19 era, the way forward is to integrate public health systems and health services to include: clinical care, surveillance and rapid response to prevalent infectious and emerging diseases, a population health approach and a recognition of improved health as both a result of the social determinants of health and a social goal that requires multisectoral action. In a recent issue of the Bulletin of the WHO, Rasanathan and Evans ${ }^{10}$ have reviewed the history of implementing the PHC vision highlighting the challenges to adapt the objectives of Astana. Their clear and precise analysis addresses how global organisations and national governments need to pursue these objectives, and the policies and objectives of the Sustainable Development Goals (SDG).

Building on their contributions, this paper identifies how the challenges can be met in practice. It identifies three silos of healthcare provision-service delivery, UHC and community participation-which have blocked health improvements. It shows how breaking these silos by strengthening public health systems contributes to effective responses to COVID-19 and to improving population health in the future.

\section{THE SILO OF HEALTH SERVICE DELIVERY}

PHC as a strategy and as a philosophy revolutionised the way in which health improvements could be achieved and, consequently, how models for organising, financing and delivering care could be greatly improved. PHC emphasised the need for:

an integrated approach of preventive, curative and promotive services for both the community and the individual; for interventions to be undertaken at the most peripheral and accessible level of the health services by the workers most simply trained for this activity; for other echelons of services to be designed in support of the needs of the peripheral level; and for PHC services to be fully integrated with the services of the other non-health sectors involved in community development. ${ }^{11}$

Despite this vision, PHC has focused on health service delivery within static health 
units often with a sole provider and the "command and control' approach to disease control. ${ }^{12}$ It fossilised the ability of most governments to provide an adequate response to the COVID-19 pandemic. The Organisation for Economic Co-operation and Development ( $p$ $34)^{13}$ examined how the traditional approach to health services was obsolete. The report highlighted the need for change to include multidisciplinary involvement, to address equity beyond financing UHC by embracing the social determinants of health and to expand peoplecentred healthcare by genuine engagement of patients and members of the community.

In practice, there is growing experience for breaking this silo. In many settings, multiskilled teams consisting of social workers and health professionals address drug addiction, mental health, nutrition and, when appropriate, patient care. Cuba's universal public health system has the ability to mobilise and adapt its considerable human and logistical resources to confront changing situations, despite material resource constraints. Cuba's large labour force pursues PHC with committed teams of family doctors and nurses who live in communities where they are highly trusted. ${ }^{14}$ Since 1993, Costa Rica's care has been delivered by basic comprehensive healthcare teams (Equipo Básico de Atención Integral en Salud in Spanish) made up of a doctor, nurse assistant and a PHC technical assistant in which each has clearly defined roles. ${ }^{15}$ Similarly, Brazil's family health strategy is implemented by doctor-nurse-community health worker (CHW) teams. ${ }^{16}$ France and Belgium have recently begun to expand the training of primary care teams to include health promotion and disease prevention. In the USA and Canada, community pharmacists and CHWs form support networks in some settings. These teams are able to be more effective in meeting patients' clinical needs and make better use of the time and effort of physicians; they also reduce costs and improve technical efficiency while promoting equitable access to service. ${ }^{13}$ In addition, patient-centred healthcare is taking much greater prominence in the area of service delivery and treatment. This approach entails a shared decision-making model where doctors and patients are jointly responsible for making treatment decisions, with a relationship that is based on trust. ${ }^{17}$

The COVID-19 pandemic unravelled the false dichotomy between health and social services. In order to effectively implement home quarantine and other public health measures while ensuring continuity of essential health services, governments had to provide basic social services such as food, medications and economic relief for low-income families, emergency programmes for the homeless and childcare for frontline health workers with young children. In Italy, the UK and Spain, the legislation that guaranteed essential social services was used to prioritise continuity of care for the most vulnerable. ${ }^{18} \mathrm{In}$ the USA, a stimulus package of $\$ 6.3$ billion was allocated for provision of social services support for children and economic relief for economically disadvantaged groups. ${ }^{19}$
There is now greater acknowledgement of the need for health systems to address social determinants of health to ensure access to comprehensive quality services. The newly launched revised framework of the essential public health functions in the Americas ${ }^{20}$ advocates the development of enabling integrated public health policies. The aim is to integrate multisectoral collaboration and collective action with the community and stakeholders to develop health and social policies. These policies focus not only on ensuring the provision of public services and public goods essential to protecting the health of the community. They also include working on the social determinants of health and setting criteria and parameters to guide the strengthening and reform of health systems. This perspective was laid out in the Alma Ata Declaration and many countries demonstrated substantial improvements due to their intersectoral approaches to health. ${ }^{21}$

\section{THE SILO OF UHC}

The Alma Ata Declaration identified health equity as a critical component for health improvements. The global economic crises of the 1970s and 2008 which removed money from governments in low-income and middleincome countries that supported programmes for health and education for those in poverty highlighted the need to put a policy into practice. UHC became the call for action. The World Health Report 2010 entitled 'Health Systems Financing: The Path to Universal Coverage ${ }^{, 22}$ gave guidance on providing health services for all based on quality, access and prevention of catastrophic health payments. However, UHC was siloed into financing services without considering the importance of social determinants of health and of community involvement in decisions about raising and allocating the funds. In addition, health economists among others raised concerns about how low-income and middle-income countries could mobilise funds for $\mathrm{UHC}^{23}$ and whether most governments would honour commitments to implement this policy.

The silo of UHC focusing on paying for healthcare services raises considerable challenges to how health improvements can be met. First is the cost of curative care for which the most part is provided in hospitals and health centres and the cost of medicines for cure. ${ }^{13}$ WHO found that based on a study of 300 cases, hospitals could achieve the same outcomes for $15 \%$ less spending. For global spending of healthcare, it is estimated that medicines account for $20 \%-30 \%$ of the budget with a slightly higher cost in low-income and middle-income countries. ${ }^{22}$ Second is the question about how the cost of services addresses prevention. Although prevention is a key component in health service provision, compared with curative services, it receives less attention and investment. As a result, allocation of health service provision does not maximise the possibility of critical health improvements for the population. A study investigated an integrated prevention 
campaign programme for diarrhoea, malaria and HIV in 70 countries assessing cost-effectiveness as measured by the cost per Disability-Adjusted Life Years (DALY) gain. The results gave evidence that in many of the countries the approach was cost-effective and had the potential to reduce the disease burdens particularly in resource-poor countries. ${ }^{24}$ Thinking more broadly and especially in lowincome and middle-income country contexts, infrastructure improvements that contribute to community health (eg, water and sanitation investments), which may have substantial health benefit and have been identified since the times of the Alma Ata Declaration, are not considered within UHC. The consequences of this oversight are especially clear during a pandemic for which clean water and sanitation are essential parts of the public health response.

The COVID-19 pandemic has demonstrated the need to break the silo of focusing on payment for health services. As highlighted in the previous section, transforming countries' health systems to be able to address future challenges requires financing for UHC that does not focus solely on the procurement and provision of curative health services. An example for breaking the silo is the 'strategic purchasing' approach whereby government buys supplies consistent with projected needs such as health emergencies has been seen as a foundation for health system responsiveness in a pandemic. Investments focusing on this component of health service provision played a pivotal role in enabling quick responses for COVID-19. ${ }^{25}$

In rebuilding improved health systems in a postCOVID-19 era, it is necessary to consider making greater investments to improve core capacities as required by health security. ${ }^{26}$ The Lancet COVID-19 Commission Statement ${ }^{27}$ advocates meeting urgent fiscal needs, particularly financing social services and social protection programmes. UHC means equitable access to health services by citizens and everyone including migrant workers and their dependents. For example, to contain transmission, migrants, living in crowded dormitories and mostly affected by COVID-19, need to have access to all laboratory tests and treatments.

However, it also is necessary for greater investments in One Health approaches where multiple disciplines work together to ensure the health of environments, humans and animals to be able to survive this pandemic and to prevent future ones. ${ }^{28}$ Progressive changes in climate and extreme weather events cause shifts in the ranges and movement of all living organisms. ${ }^{29}$ The future envisioned by the Western Pacific Region of the WHO includes health security, including antimicrobial resistance and climate change. ${ }^{30} \mathrm{~A}$ focus on UHC must include One Health and climate mitigation efforts, expanded efforts on health prevention and health promotion and public health infrastructure approaches.

\section{THE SILO OF COMMUNITY PARTICIPATION}

Community participation also was one of the two principles in the Alma Ata Declaration. Catching the imagination of WHO delegates, several countries began CHW programmes inspired by the 'barefoot doctors' in China where local people were trained to provide firstline care to their communities and become 'agents of change'. ${ }^{31}$ However, early efforts were not sustained. ${ }^{32}$ They were costly and challenged to train and support CHWs and to integrate CHWs into existing government health systems. Only a small number of countries were able to do so. A wide interest in CHWs was revived in 2000s as the HIV/AIDS epidemic took a heavy toll on existing health workers. WHO in the World Health Report ${ }^{33}$ encouraged the expansion of CHW programmes. By 2012, the US Agency for International Development and the Earth Institute at Columbia University had published strong arguments and in-depth guides to promote using CHWs particularly in low-income and middle-income countries. ${ }^{34} 35$ A review documents their impressive contribution to health particularly in the area of mother and childcare and HIV/AIDS. ${ }^{36}$ However, this focus siloed community participation as part of health service delivery.

There has been a growing realisation of the need to expand healthcare not to the community but in and with the community. Experiments in bringing community concerns as part of government planning have been evolving. A model for engagement at the national level is the National Health Assembly in Thailand. ${ }^{37}$ The National Health Act of 2007 created this body to ensure participatory involvement of the population in discussion about healthcare. The Assembly which meets every year brings together government officials, politicians, civil society members and researchers for dialogues which are not binding but influential in shaping policy. It ensures that community views have a structured place for input into health policy. In Italy, Tuscany established mechanisms to include community participation in government structures responding to both community engagement and empowerment. ${ }^{38}$ In Kenya, Dr Andrew Mulwa, Minister of Health Services in Makueni County, developed a public participation framework that systematically lays out expectations of various community organisations and their roles to participate and shape healthcare in the county. ${ }^{39}$

More widespread is the establishment in several countries of health committees composed of local people as a means to engage citizens in healthcare issues and provide accountability mechanisms for the management of these services. ${ }^{40}$ Also expanding is the development of groups to promote social accountability of local healthcare providers to address issues around quality of care and respond to specific health needs. These groups are mainly supported by non-governmental organisations and global movements including People's Health Movement $^{41}$ and the Community Practitioners on Accountability and Social Action in Health. ${ }^{42}$

COVID-19 has highlighted the critical role of community engagement and empowerment in preventing infection and minimising its impact. Based on previous 
experiences in HIV/AIDS and Ebola, there is evidence for the necessity of including communities in prevention and control. These experiences show that communities are not simply an add-on but are a fundamental contribution to control programmes. They need to be partners and coproducers for successful outcomes. In the Lancet, ${ }^{43}$ Marston and colleagues outline three steps to incorporate local people. The first is for governments to establish and fund community engagement task forces to integrate local responses to health and social actions and to coordinate links with sectors including police and education. The second is to help existing networks to support health providers and ensure the needs of the most vulnerable are being met. Third is for policymakers to show community people that their needs are recognised and heard and corrective measures are introduced. Responses to self-employment, traffic control and road closures and home medication to reduce exposure of people to health facilities are examples. Responses to COVID-19 have the potential to integrate community participation and empowerment into health systems through coproduction of response. They can contribute to the integration of public voices in decisions and action for health beyond services and give specific recognition and structure to community participation in healthcare.

\section{THE WAY FORWARD: TRANSLATING THE WHO DEFINITION OF HEALTH INTO PRACTICE}

Breaking these three silos of traditional healthcare provision is critical to improving health and well-being. The COVID-19 crisis has highlighted weaknesses in healthcare systems in most countries. COVID-19 has shown most countries have not organised and financed their health services adequately to address the pandemic and have not invested enough resources in public health. The underinvestment is a reflection of the limited emphasis in prevention and health promotion compared with clinical care. It highlights the failure to address the needs of those living in conditions of vulnerability who require access to both health and social support services. ${ }^{44}$

Population-based and individual, personal care services are complementary. When implemented in a coordinated way, there is good potential for each to enhance the other. Public health functions that are relevant and closely linked to a PHC approach and primary care delivery are health protection, health promotion, and disease prevention, surveillance and response, and emergency preparedness. The integration of public health in systems with a strong PHC foundation and UHC has the potential for a comprehensive, proactive approach. It enables systems to be responsive in the face of health emergencies.

Over the past decades, both international organisations and national governments have developed policies and healthcare structures to address PHC to incorporate the values of equity, participation and social determinants. Beyond adjusting health services to meet health needs, there is a growing recognition that the social determinants of health are critical for addressing health improvements. Most recently, the importance of social determinants has been clearly articulated in the UN promulgation of the SDGs. ${ }^{45}$ An article in the Lancet $^{46}$ draws out in detail how the approaches of PHC as defined by the WHO Commission on the Social Determinants of Health ${ }^{47}$ underlie important goals of the document including reducing poverty (SDG 1), addressing hunger and malnutrition (SDG 2), expanding education and employment opportunities (SDG 4 and 8) and addressing environmental pollution (SDG 6 and 7). PHC calls for a multisectoral approach for coordinated efforts of 'all related sectors and aspects of national and community development, in particular agriculture, animal husbandry, food, industry, education, housing, public works, communications and other sectors'. ${ }^{47}$ However, challenges remain for integrating health objectives into non-health sectors and building bridges to create mechanisms and to address cultural differences. The process of transforming traditional views with the dominance of health services as the sole actor for health improvements demands more discussions. Challenges remain to develop a 'shared vision' of safeguarding health of the people by non-health sectors, creating policy coherence and bridging the difference in organisation culture and conflicting mandates across government sectors, such as between trade and economic growth and health and environment protection.

\section{CONCLUSION}

In 2008, the Commission on the Social Determinants of Health of the WHO stated, 'The Alma Ata Declaration promoted PHC as its central means towards good and fair global health-not simply health services at the primary care level (though that was important), but rather a health system model that acted also on the underlying social, economic and political causes of poor health'. ${ }^{47}$ Loewenson and colleagues have investigated how a comprehensive public health system is critical in a post-COVID-19 world. $^{4}$ The paper argues that to deal with the 21st-century threats, a public health system must be built on comprehensive, participatory, multidisciplinary approach addressing the social determinants to deal with issues of climate change, food and energy crisis, inevitable pandemics and armed conflicts. These challenges can only be met if the traditional silos of health provision are dismantled. PHC was visionary 40 years ago. Today, the COVID-19 pandemic demands the vision be translated into practice.

Acknowledgements This paper would not have been submitted without the encouragement and support of Dr Seye Abimbola and Dr Stephine Topp. Dr Edwin Bolistag contributed his wisdom and experience from working in Latin America.

Contributors SBR conceived the topic. The coauthors added information and experience.

Funding The authors have not declared a specific grant for this research from any funding agency in the public, commercial or not-for-profit sectors.

Competing interests None declared. 
Patient consent for publication Not applicable.

Provenance and peer review Commissioned; internally peer reviewed.

Data availability statement Data are available in public,open access repository.

Open access This is an open access article distributed in accordance with the Creative Commons Attribution Non Commercial (CC BY-NC 4.0) license, which permits others to distribute, remix, adapt, build upon this work non-commercially, and license their derivative works on different terms, provided the original work is properly cited, appropriate credit is given, any changes made indicated, and the use is non-commercial. See: http://creativecommons.org/licenses/by-nc/4.0/.

ORCID iD

Susan B Rifkin http://orcid.org/0000-0001-5482-7829

\section{REFERENCES}

1 WHO, Constitution of the World Health Organization. Supplement to basic documents. 45th ed. Switzerland: United Nations Geneva, 2006.

2 Byrant J, Richmond J. Alma Ata and primary health care: an evolving story, in international encyclopedia of public health 2008:152-74.

3 Statista. Number of novel coronavirus (COVID-19) deaths worldwide as of October 6,2021 , by country 2021, 2021. Available: https:// www.statista.com/statistics/1093256/novel-coronavirus-2019ncovdeaths-worldwide-by-country/

4 Loewenson R, Accoe K, Bajpai N, et al. Reclaiming comprehensive public health. BMJ Glob Health 2020;5:e003886.

5 Worldometer. COVID-19 coronavirus pandemic: coronavirus cases, 2021. Available: https://www.worldometers.info/coronavirus/?utm campaign=homeAdvegas 1

6 Bigdeli M, Rouffy B, Lane BD, et al. Health systems governance: the missing links. BMJ Glob Health 2020;5:e002533.

7 Larson H, Simas C, Horton R. The emotional determinants of health: The Lancet-London School of Hygiene \& Tropical Medicine Commission. Lancet 2020;395): :768-9.

8 WHO. Declaration of Astana, 2018. Available: https://www. who. int/publications/i/item/WHO-HIS-SDS-2018.61 [Accessed 29 Sep 2021].

9 WHO, The 2018, World Health Organization and the United Nations Children's Fund Geneva.

10 Rasanathan K, Evans TG. Primary health care, the Declaration of Astana and COVID-19. Bull World Health Organ 2020;98:801-8.

11 Litsios S. On the Origin of Primary Health Care. In: Medcalf A, ed. Health for all: the journey of universal health coverage. Hyderabad: Orient Blackswan, 2015. https://www.ncbi.nlm.nih.gov/books/ NBK316278/

12 WHO. The world health report: now more than ever. Geneva: World Health Organization, 2008.

13 OECD. Realising the potential of primary health care, in OECD health policy studies, 2020. Available: https://www.oecd-ilibrary.org/sites/ 8399d5a7-en/index.html?itemld=/content/component/8399d5a7-en

14 Aguilar-Guerra TL, Reed G. Mobilizing Primary Health Care:Cuba's Powerful Weapon against COVID-19. MEDICC Rev 2020;22): :53-7.

15 Spigel L, Pesec M, Villegas Del Carpio O, et al. Implementing sustainable primary healthcare reforms: strategies from Costa Rica. BMJ Glob Health 2020;5:e002674.

16 Wadge H, Bhatti Y, Carter A. Brazil's Family Health Strategy: Using Community Health Workers to Provide Primary Care. Commonwealth Fund, 2016.

17 Nolte E, Merkur S, Anell A, eds. Achieving Person-Centred Health Systems: Evidence, Strategies and Challenges European Observatory on Health Systems and Policies. Cambridge: Cambridge University Press, 2020.

18 Lara Montero A. Social services and Covid19: supporting the frontline, 2020. Available: https://www.esn-eu.org/news/socialservices-and-covid19-supporting-frontline [Accessed 9 Oct 2021].

19 Administration for Children and Families, U.S. Department of Health \& Human Services. ACF-COVID-19-Stimulus, 2020. Available: https://www.acf.hhs.gov/coronavirus/acf-covid-19-stimulus [Accessed 9 Oct 2021].

20 Bascolo E, Houghton N, Del Riego A, et al. A renewed framework for the essential public health functions in the Americas. Rev Panam Salud Publica 2020;44:1.

21 Balabanova D, McKee M. A 'Good health at low cost'-25 years on. London: London School of Hygiene and Tropical Medicine, 2011.

22 WHO. The world health report: health systems financing: the path to universal coverage. Geneva: World Health Organization, 2010.
23 Rifkin SB. Alma Ata after 40 years: primary health care and health for All-from consensus to complexity. BMJ Glob Health 2018;3:e001188.

24 Marseille E, Larson B, Kazi DS, et al. Thresholds for the costeffectiveness of interventions: alternative approaches. Bull World Health Organ 2015;93:118-24.

25 Gatome-Munyua A, Yemane $\mathrm{H}$, English A. Coordinating, financing and paying for COVID-19 health services: a synthesis of lessons and best practices from country experience, 2020. Available: https://r4d. org/wp-content/uploads/Synthesis-JLNPHCFinancingandPaymen tCaseStudies.pdf [Accessed 9 Oct 2021].

26 WHO. International health regulations. Geneva, Switzerland, 2005. Available: https://www.who.int/publications-detail-redirect/ 9789241580496 [Accessed 8 Oct 2021].

27 Lancet Covid-19 commissioners, Task force chairs, and Commission Secretariat, Lancet COVID-19 Commission statement on the occasion of the 75th session of the UN General assembly. The Lancet 2020;396:1102-24.

28 Centers for Disease Control and Prevention (CDC) and U.S. Department of Health \& Human Services. One health. Available: https://www.cdc.gov/onehealth/index.html [Accessed 9 Oct 2021].

29 Deem SL, Brenn-White M. One Health-the key to preventing COVID-19 from becoming the new normal. Mol Front J 2020;4:30-5.

$30 \mathrm{WHO}$. For the future: toward the healthiest and safest region. Western Pacific Regional Office, 2020. Available: https://iris.wpro. who.int/bitstream/handle/10665.1/14476/WPR-2020-RDO-001-eng. pdf [Accessed 1 Sep 2021].

31 Weiyuan C. China's village doctors take great strides. Bull World Health Organ 2008;86:914-5.

32 WHO. The world health report: working together for health. Geneva: World Health Organization, 2006.

33 Walt G. Community health workers in national programmes: just another pair of hands? Milton Keynes: Open University Press, 1990.

34 USAID and Maternal and Childre Health Integrated Program (MCHIP). Developing and strengthening community health worker programs at scale: a reference guide for program managers and policy makers. Washington, DC: USAID Bureau for Global Health, 2013.

35 Earth Institute. On million community health workers: technical Task force report. New York: Columbia University, 2012. http://1mil lionhealthworkers.org/files/2013/01/1mCHW_TechnicalTaskFor ceReport.pdf

36 Perry HB, Zulliger R, Rogers MM. Community health workers in low-, middle-, and high-income countries: an overview of their history, recent evolution, and current effectiveness. Annu Rev Public Health 2014;35:399-421.

37 Rajan D, Mathurapote N, Putthasri W, et al. Institutionalising participatory health governance: lessons from nine years of the National health assembly model in Thailand. BMJ Glob Health 2019:4:e01769.

38 Odone A, Saccani E, Chiesa V, et al. The implementation of a community health centre-based primary care model in Italy. The experience of the case DELLA salute in the Emilia-Romagna region. Ann Ist Super Sanita 2016;52:70-7.

39 Government of Kenya. Public participation framework. Available: https://makueni.go.ke/public-participation-framework [Accessed 9 Oct 2021].

40 George A, Scott K, Garimella S, et al. Anchoring contextual analysis in health policy and systems research: a narrative review of contextual factors influencing health committees in low and middle income countries. Soc Sci Med 2015;133:159-67.

41 People's Health Movement. The people's charter for health, 2002. Available: phm-pch-english.pdf [Accessed 9 Oct 2021].

42 COPASAH. Community practitioners on accountability and social action in health. Available: https://www.copasah.net [Accessed 9 Oct 2021].

43 Marston C, Renedo A, Miles S. Community participation is crucial in a pandemic. Lancet 2020;395:1676-8.

44 Etienne CF, Fitzgerald J, Almeida G, et al. COVID-19: transformative actions for more equitable, resilient, sustainable societies and health systems in the Americas. BMJ Glob Health 2020;5:e003509.

45 UNDP. Sustainable development goals. Available: https://www.undp. org/sustainable-development-goals [Accessed 9 Oct 2021].

46 Hone T, Macinko J, Millett C. Revisiting Alma-Ata: what is the role of primary health care in achieving the sustainable development goals? Lancet 2018;392:1461-72.

47 Commission on the Social Determinants of Health,. Closing the gap in a generation: health equity through action on the social determinants of health: final report of the Commission on social determinants of health. Geneva: World Health Organization, 2008. 